\title{
Neologismos en la prensa escrita venezolana 2011-2012: un encuentro lingüístico-cultural ${ }^{*}$
}

\author{
Neologisms and linguistic loanwords in the Venezuelan \\ press 2011-2012: a linguistic-cultural approach
}

Neologismos e empréstimos lingüistico na imprensa venezuelana 2011-2012: um encontro lingüistico-cultural

Recibido el 18 de julio de 2016. Aceptado el 28 de noviembre de 2016

\author{
Oscar Elías Blanco Correa** \\ Venezuela \\ Jessica del Valle Pacheco*** \\ Venezuela
}

- Para citar este artículo:

Correa, Oscar Elías y Valle, del

Pacheco, Jessica (diciembre,

2016). Neologismos en la prensa escrita venezolana 2011-2012:

un encuentro lingüísticocultural. Ánfora, 23(41), 55-84.

Universidad Autónoma de Manizales. ISSN 0121-6538.

\section{Resumen}

Objetivo: identificar los neologismos y préstamos lingüísticos como elementos léxicos de mediación entre dos culturas presentes en la prensa escrita venezolana, en el periodo 2011-2012; igualmente, se busca construir un inventario lexicográfico con los neologismos y préstamos lingüísticos. Metodología: mediante el método lexicográfico y el de verificación del neologismo y préstamo lingüístico se identificaron, recopilaron, analizaron y describieron los fenómenos léxicos y la relación que se establece entre dos culturas, a partir de

\footnotetext{
* Artículo derivado de Investigaciones sobre el uso de los neologismos en el léxico de uso venezolano (Proyecto actualmente en ejecución). De este proyecto ha surgido la ponencia Neologismos y préstamos lingüísticos ¿Mediación entre culturas? dictada en XXV Simposio Internacional de la Asociación Venezolana de Estudio del Caribe celebrado en la Universidad de Carabobo en abril de 2012, la cual se continúa desarrollando desde marzo 2013 hasta julio de 2016.

** Magister en Lingüística. Lexicógrafo. Profesor de la Universidad Simón Bolívar-Sede Litoral. Correo electrónico: eblanco@usb.ve

*** Lexicógrafa. Profesora de la Universidad Simón Bolívar-Sede Litoral. Correo electrónico: jessicapacheco@usb.ve
} 
su uso. El corpus proviene de las fuentes hemerográficas, en este caso la prensa escrita venezolana, entre 2011-2012. Resultados: se obtuvo un conjunto de neologismos (estandupero, -a, buena vibra, imparable, entre otros) y préstamos lingüísticos (team work, dogout, baby gym) que relacionan dos culturas diferentes. Al mismo tiempo, funcionan como el encuentro, mediación y apropiación de realidades distintas, debido al uso y adopción de estos fenómenos. Se consolidó un inventario lexicográfico como un artefacto cultural que informa y muestra las particularidades léxicas que se analizaron: neologismos y préstamos lingüísticos. Conclusión: se concluye que los neologismos y préstamos lingüísticos median y relacionan las dos culturas. También enriquecen los procesos comunicativos, ya que estos nuevos vocablos y/o unidades léxicas se introducen y adaptan en un sistema lingüístico por conversión, calco o invención de forma.

Palabras claves: Neologismos, Lingüística, Interculturalidad

\section{Abstract}

Objective: to identify neologisms and linguistic loanwords as lexical items of mediation between two cultures in the Venezuelan press between 2011-2012. Similarly, this aims at building a lexicographical inventory with the neologisms and linguistic loanwords Methodology: the lexical phenomena were collected, identified and described by using the lexicographical method and the neologism and linguistic loanword verification, in addition to this, a relationship was established between the two cultures from their use. The corpus comes from newspaper sources, in this particular case the Venezuelan press between 2011-2012. Results: a set of neologisms were collected (estandupero,-a buena vibra, imparable among others) and linguistic loanwords (team work, dogout, baby gym) that relate two different cultures. These also work as an approach, mediation and appropriation of different realities, due to the use and adoption of such phenomena. A lexicographical inventory was consolidated as a cultural artifact that reports and shows the lexical peculiarities that were analyzed: neologisms and linguistic loanwords. Conclusion: it is concluded that neologisms and linguistic loanwords mediate and relate the two cultures. Also, they enrich the communication processes, as these new words and / or lexical items are introduced and adapted in a language conversion system, calque or invention of form.

Keywords: Neologisms, Linguistics, Interculturality 


\section{Resumo}

Objetivo: identificar neologismos e empréstimos linguísticos como elementos lexicais de mediação entre duas culturas presentes na imprensavenezuelana, no período 2011-2012; Além disso, procura-se construir um inventário lexicográfico com os neologismos e empréstimos linguísticos. Metodologia: usando o método lexicográfico e o de verificação do neologismo e empréstimo linguístico, foram identificados, recopilados, analisados e descritos os fenômenos lexicais e a relação estabelecida entre duas culturas, a partir de seu uso. O corpus é proveniente de fontes hemerográficas, neste caso, a imprensa venezuelana, entre 2011-2012.Resultados: obteve-se um conjunto de neologismos (estandupero, -a, buena vibra, imparable, entre outros) e estrangeirismos (team work, dogout, baby gym), que ligam duas culturas diferentes Ao mesmo tempo, funcionam como o encontro, mediação e apropriação de diferentes situações, devido ao uso e adoção desses fenômenos. Um inventário lexicográfico foi consolidado como um artefato cultural que informa e mostra as peculiaridades léxicas que foram analisadas: neologismos e empréstimos linguísticos. Conclusão: conclui-se que os neologismos e empréstimos linguísticos mediam e ligam as duas culturas.Também eles enriquecem os processos de comunicação, uma vez que estas novas palavras e / ou unidades lexicais são introduzidas e adaptadas em um sistema linguístico por conversão calco ou invenção da forma.

Palavras-chave: neologismos, Linguística, interculturalidade 


\section{Introducción}

La lengua es un sistema de signos verbales y, al mismo tiempo, constituye la norma por la que se rige un grupo de hablantes para relacionarse y comunicarse entre sí. Esta apreciación permite concebirla como una institución sociocultural, abierta, dinámica y heterogénea. En ese sentido, las afirmaciones de Baldinger (1970) aseveran esta premisa al indicar que "vemos el mundo a través de las gafas de nuestra lengua, es decir, expresado más científicamente, por medio de conceptos, de objetos mentales, de los esquemas de representación de nuestra lengua materna” (p. 103).

Lo anterior sugiere que la lengua define a la persona y a la comunidad que lo rodea y, a la vez, puede mostrar sus formas de pensar, actuar y sentir, así como su visión del mundo y las perspectivas que asumen; ello, evidencia un sentido de pertenencia e identidad (Chela-Flores, 1998, p. 1), que se encuentra en permanente cambio y que repercute de manera directa e indirecta en la adquisición de nuevas formas de expresión (Otaola, 2004, p. 59).

Estas nuevas formas de adquisición y/o cambios, según Otaola (2004, p. 59), se producen en los componentes fonológico, morfológico, sintáctico, semántico y léxico. En este último componente, el léxico, las transformaciones han sido mucho más rápidas en comparación con las normas gramaticales, dadas las múltiples creaciones, movimientos e incorporaciones de diferentes elementos lingüísticos como frases, expresiones, apodos, palabras altisonantes, neologismos y préstamos lingüísticos que pueden evidenciar.

El hecho de que el léxico incorpore e introduzca nuevas lexías -como los neologismos y/o préstamos lingüísticos- se debe a su permeabilidad y susceptibilidad a las innovaciones y admisiones de nuevas unidades que identifican, designan o describen algún aspecto (acción, evento, objeto) de las relaciones humanas. Esta premisa permite establecer el léxico, a juicio de Lara (2006), como un símbolo social porque las palabras -lexemas- que lo componen "trascienden su naturaleza de signos lingüisticos y se convierten en representantes de concepciones, valores, $y$ tabúes sociales, a los que se les atribuyen propiedades mágicas hasta funciones morales e ideológicas" (p. 213).

De este modo, el léxico evidencia el accionar social y cultural de una comunidad, porque dispone de una serie de recursos y unidades significativas (lexemas) que facilitan la competencia lingüística (Otaola, 2004, p. 27). Así, decimos que el léxico de una lengua se encuentra organizado en lexemas -provistos de dinamis- 
mo, movilidad y elementos de identidad- que denominan, refieren y significan una persona, una particularidad o una situación. Entre los cambios y dinamismo que presenta este componente lingüístico se destacan, según Otaola (2004, p. 60), los siguientes: a) la llegada de nuevas palabras (creación-neologismos); b) la revitalización o reutilización de palabras ya existentes (renovación, neologismos semánticos, préstamos); y c) la pérdida de palabras viejas, aunque algunas después pueden volver como neologismos.

De la anterior apreciación, resaltan los neologismos y préstamos lingüísticos. En el caso de los neologismos, Otaola (2004) los define como "el proceso por el que el cambio lingüístico provoca la aparición de forma y sentidos nuevos" (p. 65). Por eso, este fenómeno léxico aparece cuando se ha creado o formado otra lexía desde el punto de vista estructural, o bien cuando se le ha asignado un nuevo significado. En el mismo orden de ideas, Alcoba Rueda (2007) asevera que el neologismo es:

(...) una palabra, una acepción o una frase (combinación fija de palabras) nueva en el conjunto de unidades comunicativas de que dispone el hablante.

O sea que se considera neologismo una palabra enteramente nueva (en forma de expresión y en significado), una palabra parcialmente nueva (que incorpora un significado o acepción nuevos) o un giro o combinación de palabras (dinero negro) usado con un sentido particular (p. 24).

De lo expresado por el autor se desprende que, este fenómeno léxico designa y describe la cosa o situación desconocida. A su vez, permite la incorporación y uso de la palabra recién creada, lo que propicia el entendimiento y comprensión de un hecho por un grupo lingüístico. Esto significa que una lexía se considera un neologismo cuando es de reciente data y no se ha incorporado a un repertorio lexicográfico, es decir, diccionario, glosario, u otros repertorios; así, desde el momento en el que la nueva palabra se incluye en alguno de los artefactos antes mencionados, pierde dicha condición, para convertirse en una lexía propia del sistema lingüístico al que se circunscribe, tal como lo apunta Castillo (2003): "se puede afirmar que cuando algunos diccionarios, esencialmente descriptivos, comienzan a recoger las nuevas voces, se da un primer paso hacia la desneologización, que probablemente se consuma con la entrada en el DRAE” (p. 96).

Esta particularidad ocurre, también, con los préstamos lingüísticos, que a juicio de Martínez (s. f.) se conciben como: 
(...) todo elemento tomado de otra. Decimos "elemento" y no "palabra" porque las palabras constituyen solo la clase más trascendental de los préstamos. Hemos de añadir, para completar la definición, que también es préstamo cualquier elemento lingüístico tomado de un dialecto, incluso de la misma nación que la lengua y viceversa. (p. 189).

Del planteamiento de Martínez (s. f.) se desprende que una lengua toma una unidad léxica, en este caso un préstamo, de otro sistema lingüístico para incorporarlo a su estructura interna porque, quizás, carezca de dicha unidad para nombrar y/o describir una situación determinada. Ello implicaría que el préstamo lingüístico se resemantice y/o cambie en su forma para explicar elementos concernientes y provenientes de otras culturas y, por ende, adaptarse a aquella que lo adopta. En este sentido, los préstamos lingüísticos permiten la incorporación de signos y símbolos foráneos, lo que propicia la reciprocidad y convivencia de dos grupos lingüísticos y culturales divergentes. Al mismo tiempo, resultan novedosos y sirven para ampliar el espectro psico-socio-lingüístico-cultural de un grupo de hablantes, ya que nominaliza, designa y describe aquellos elementos novedosos, que se hayan originados por la dinámica cotidiana.

De esta manera, los préstamos lingüísticos y los neologismos, en general, contemplan una información cultural que, una vez admitida y aceptada, adopta e impone nuevas realidades, sobre todo si se asume que la lexía -palabra- lleva consigo ideas, formas de vida originales y disímiles. Por lo tanto, se evidencia que a través de los neologismos y los préstamos lingüísticos median dos culturas distintas, cuyas unidades léxicas pueden ser las ideales para transmitir otras maneras de pensar, sentimientos, visión y percepción del mundo.

Asimismo, recurrir a estos fenómenos léxicos agiliza la comunicación, el entendimiento e la interrelación entre los integrantes de una comunidad lingüística, cuando en la lengua materna no exista o no se encuentre la lexía adecuada para designar o explicar algún evento. Así lo evidencian las investigaciones de Quiroga (1991), quien ha abordado los neologismos desde su formación y la forma cómo estos se han integrado a la variedad lingüística venezolana. Igual lo hace Lugo (1996), pero, a diferencia del anterior, se concentró en el impacto de ellos en el campo económico y sus implicaciones en las redes sociales; mientras que Meza, Arrieta y Batista (2007) han planteado la necesidad de su uso en el caso de los docentes y estudiantes así como su resistencia a adoptarlos dentro y fuera del aula. 
Estas investigaciones realizadas en Venezuela evidencian la importancia que los neologismos y préstamos lingüísticos dejan entrever en la variedad venezolana y en los procesos comunicativos de los hablantes de dicha variedad. Sin embargo, no se perciben, hasta ahora, aproximaciones ni estudios explicativos desde la lexicografía y mucho menos su valor lingüístico-cultural; por eso, se constituyó en uno de los motivos en la presente investigación, cuyo corpus de análisis proviene de la prensa escrita venezolana en el periodo 201 1-2012, debido a que en los medios impresos venezolanos se puede evidenciar la utilización de estos fenómenos léxicos en los diversos ámbitos de la cotidianidad, así como la mediación y convergencia de dos culturas.

Lo anterior, genera las siguientes interrogantes: ¿Cuáles neologismos y préstamos lingüísticos presentes en la prensa escrita venezolana en el periodo 2011-2012 pueden propiciar el encuentro de dos culturas? ¿Logran los neologismos y préstamos lingüísticos dinamizar y enriquecer una lengua y por extensión una variedad dialectal como la venezolana? ¿La elaboración de un inventario de neologismos y préstamos lingüísticos extraídos de la prensa escrita venezolana en el periodo 2011-2012 consigue reflejar la riqueza lingüística de dichos fenómenos léxicos?

Para dar respuesta a estas preguntas se han formulado a continuación estos objetivos: i) identificar los neologismos y préstamos lingüísticos como elementos léxicos de comunicación y mediación entre dos culturas presentes en la prensa escrita venezolana entre el periodo 2011-2012 y, ii) confeccionar un inventario lexicográfico con los neologismos y préstamos lingüísticos para reflejar su vitalidad, dinamismo, formación y adopción en una lengua. Con tales objetivos se espera comprobar la tesis planteada, así como evidenciar la importancia de estos fenómenos léxicos en los procesos comunicativos entre los hablantes de la variedad lingüística venezolana y de cómo su competencia lingüística se enriquece con la adopción de dichos fenómenos.

De igual forma, se espera que esta investigación contribuya con los estudios léxicos y en particular sobre los neologismos y préstamos lingüísticos de nuestro país. Al mismo tiempo, aportar otras perspectivas en la lexicografía, debido a que esta disciplina puede no sólo mostrar la diversidad y dinamismo de una lengua sino dar una visión, si se quiere, distinta sobre el quehacer lingüístico, su relación con la cotidianidad y cultura de un grupo de hablantes; de allí que se contemple la confección de un repertorio, en este caso, un inventario de neologismos y préstamos lingüísticos como parte de los resultados de la presente investigación, puesto que los repertorios lexicográficos son una muestra de la vitalidad de la lengua, así como la representación y reflejo de un grupo de hablantes. Para constatar lo expresado anteriormente, se ha recurrido a una metodología que se describe a continuación. 


\section{Metodología}

El corpus utilizado en la presente investigación proviene de los reportajes de cuatro medios impresos venezolanos: Últimas Noticias (UN), El Universal (EU), El Nacional (EN) y Líder (LR), seleccionado aleatoria e intencionalmente por los autores. Los tres primeros diarios abarcan la política, economía, deportes, farándula, tecnología, entre otros. Mientras que el diario Líder cubre solo el ámbito deportivo.

Para la recolección del corpus se ha dispuesto de dos momentos: noviembre de 2011 y marzo de 2012. Durante ese tiempo la lectura de los medios impresos ha sido interdiaria, es, decir, dejando un día por medio. Es importante acotar que en esta investigación no se ha hecho un análisis estadístico profundo, sólo se ha tomado la aparición de aquellos fenómenos para su interpretación léxica y posterior confección de un repertorio lexicográfico.

Para tal fin se siguieron dos métodos: el primero consiste en la verificación de los neologismos, a partir del Protocolo de vaciado de textos escritos (prensa) esbozado por el Observatorio de Neología del Institut Universitari de Lingüística Aplicada de la Universitat Pompeu Fabra de Barcelona. De igual modo, se utilizaron las concepciones de Alcoba (2007.) quien ha implementado similares técnicas para la identificación de los neologismos y su sistematización. El segundo método es el lexicográfico, de acuerdo con los preceptos de Lara (1997) y Fajardo (2010). La aplicación de estos métodos permitió la identificación de los neologismos y préstamos lingüísticos, así como su interpretación, reconocimiento y la relación que convergen entre dos culturas y que puede evidenciarse en la ordenación de un inventario léxico con los fenómenos estudiados.

Sobre el primer método, Verificación de los neologismos, se partió de la tesis del Observatorio de Neología del Institut Universitari de Lingüística Aplicada de la Universitat Pompeu Fabra de Barcelona, en lo particular del Protocolo de vaciado de textos escritos (prensa) que permite reconocer un neologismo a partir del criterio de comprobación de la unidad léxica; es decir, si aparece o no en un tex to de referencia, en este caso de un diccionario como el Diccionario de la Real Academia Española (DRAE) (2001):

Se considera neologismo documentado en el diccionario y que, por lo tanto, hay que desestimar: 
- aquel que esté registrado en una entrada propia,

- aquel que aparezca claramente identificado como subentrada dentro de una entrada más genérica (ocurre en el caso de las locuciones y algunos neologismos complejos),

- las unidades sintagmáticas que aparezcan en los ejemplos de una entrada (por ejemplo, hecho un higo dentro de la entrada higo), y

- los neologismos prefijados, sufijados o formados por composición culta mediante una forma prefijada o sufijada, en el caso de que consten como ejemplo de la entrada del afijo en cuestión (p. 6).

La aplicación de ese criterio, permitió la selección e incorporación de los neologismos y préstamos lingüísticos en el presente estudio, debido a que no aparecen registrados en el DRAE (2011). Una vez se recopilaron y contrastaron estos fenómenos lingüísticos se procedió a tipologizarlos y clasificarlos a partir del siguiente gráfico:

Gráfico 1. Tipologización y clasificación de los neologismos.

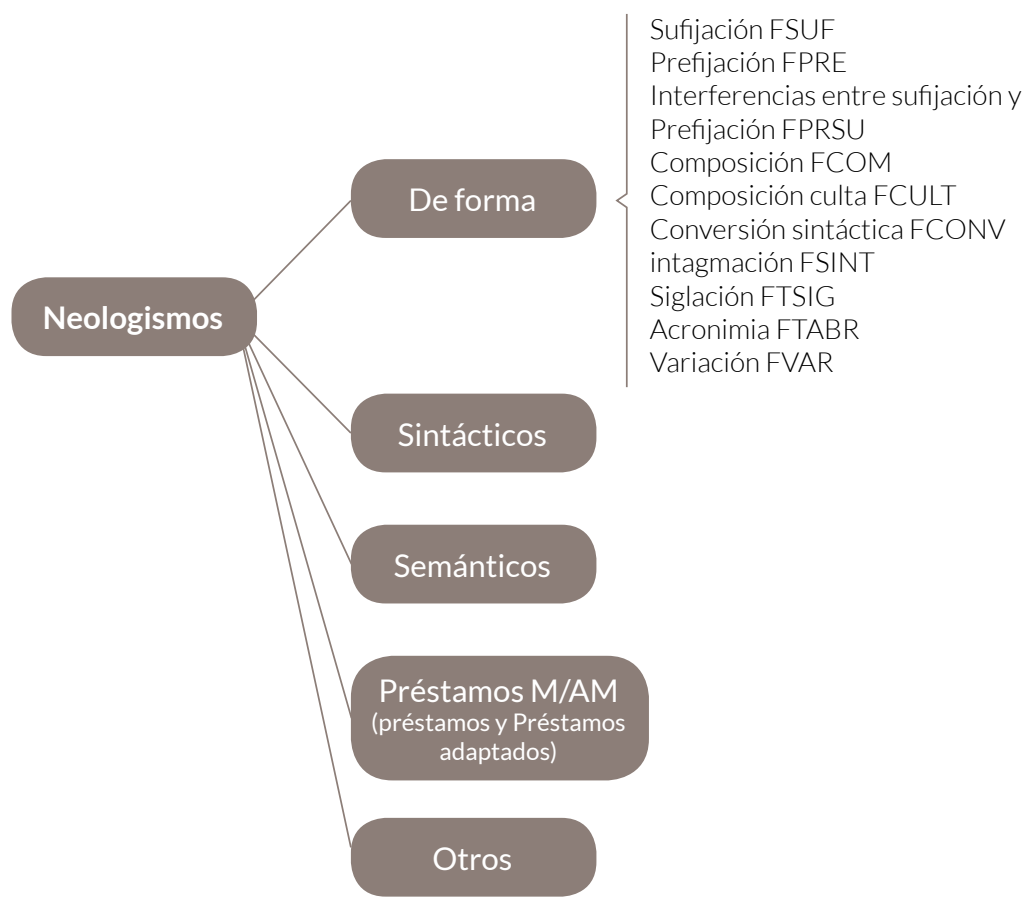

Fuente: elaboración propia 
La clasificación que muestra el gráfico permite no sólo la tipologización de los neologismos de acuerdo con las características presentadas, sino además comprenderlos. Para ello, se dispone a continuación un cuadro resumen para explicar cada una de estas tipologías:

Tabla 1. Neologismos de forma

\begin{tabular}{|c|}
\hline Neologismo de forma \\
\hline Sufijación (FSUF): Producto de la adjunción de un sufijo a un radical. \\
\hline Prefijación (FPRE): Formado por la adicción de un prefijo a un radical. \\
\hline $\begin{array}{l}\text { Interferencias entre sufijación y prefijación (FPRSU): Formación gracias a la adjunción de } \\
\text { un prefijo y sufijo en un mismo radical. }\end{array}$ \\
\hline $\begin{array}{l}\text { Composición (FCOM): Formación del neologismo por la unión de dos radicales que pueden } \\
\text { ser simples o complejos. }\end{array}$ \\
\hline $\begin{array}{l}\text { Composición culta (FCULT): Neologismo originado por una forma prefijada y una forma } \\
\text { sufijada o bien por un radical de lengua y un sufijo. }\end{array}$ \\
\hline $\begin{array}{l}\text { Lexicalización (FLEX): Producto de la lexicalización (institucionalización y uso constante) } \\
\text { de una forma flexiva (no el paradigma completo) proveniente de una forma de paradigma } \\
\text { verbal. }\end{array}$ \\
\hline $\begin{array}{l}\text { Conversión sintáctica (FCONV): Producto del cambio de categoría gramatical sin que la } \\
\text { base léxica se modifique. }\end{array}$ \\
\hline $\begin{array}{l}\text { Sintagmación (FSINT): Formación del neologismo debido a una estructura sintáctica lexicali- } \\
\text { zada. }\end{array}$ \\
\hline $\begin{array}{l}\text { Siglación (FTSIG): Neologismo que se forma por las letras que corresponden a una sigla que } \\
\text { ha perdido alguna característica y se ha lexicalizado. }\end{array}$ \\
\hline $\begin{array}{l}\text { Acronimia (FTACR): Neologismo que se produce con la combinación de segmentos de pala- } \\
\text { bras que forman una estructura sintagmática. }\end{array}$ \\
\hline $\begin{array}{l}\text { Abreviación (FTABR): Formación del neologismo a partir del acortamiento de una palabra o } \\
\text { sintagma. }\end{array}$ \\
\hline $\begin{array}{l}\text { Variación (FVAR): Variante neológica a partir de la ortografía de una palabra que ha sido } \\
\text { documentada en el corpus de exclusión. }\end{array}$ \\
\hline $\begin{array}{l}\text { Neologismo sintáctico (SINT): Neologismo que se produce por los cambios de subcategoría } \\
\text { gramatical (género, número, cambio de régimen verbal, entre otros). }\end{array}$ \\
\hline $\begin{array}{l}\text { Neologismo semántico (S): Producto de la modificación de significado de una base léxica o } \\
\text { bien originado de un nombre propio utilizado como nombre común. }\end{array}$ \\
\hline Préstamo (M/AM): Unidad léxica importada de otra lengua. \\
\hline $\begin{array}{l}\text { Otros (A): Neologismos provenientes de palabras simples, dialectales, argóticas, cultismos o } \\
\text { casos extraños difíciles de etiquetar. }\end{array}$ \\
\hline
\end{tabular}

Fuente: elaboración propia con datos tomados de Neologia (2004). 
Toda vez que se tipologizan y clasifican los neologismos y préstamos lingüísticos a partir de los presupuestos del Observatorio de Neología, se ha recurrido a la tesis de Alcoba (2007) para establecer a partir del surgimiento y formación del neologismo si es o no necesario. Estas nociones se han sintetizado en el siguiente gráfico:

Gráfico 2. Neologismos necesarios o No necesarios.

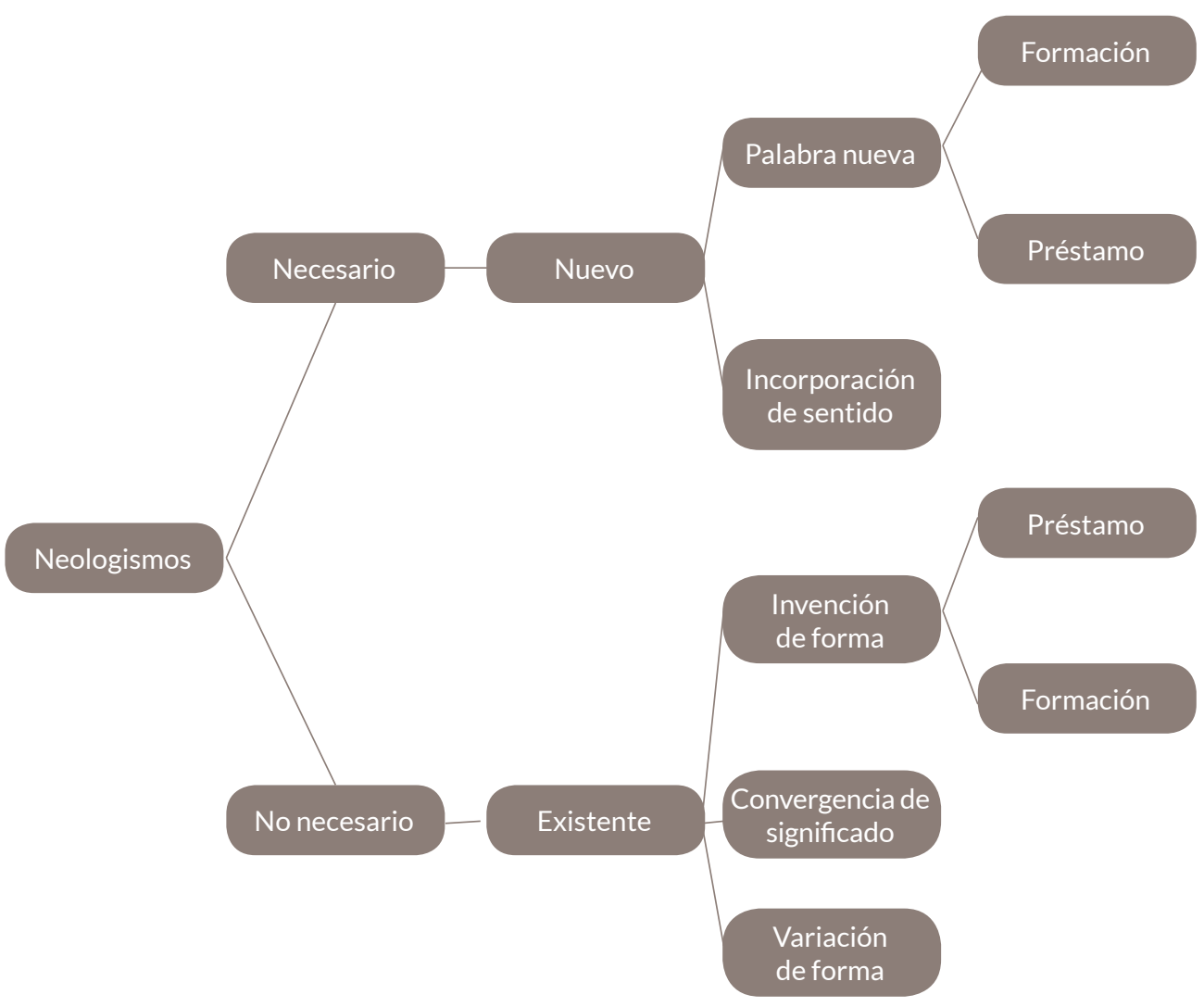

Fuente: elaboración propia con los aportes de Alcoba (2007).

Según este gráfico, un neologismo es necesario cuando una palabra nueva se obtiene de un préstamo o formación o cuando se le ha incorporado un sentido distinto y se utiliza para designar una particularidad; por ejemplo, en el presente estudio se obtuvo el préstamo lingüístico scout, que se necesita para designar una situación del día a día. Mientras que un neologismo no es necesario cuando 
existe la unidad léxica y se crean otras por invención (préstamo y formación), convergencia de significado o variación de forma; es decir, si bien surgen otras formas de denominar, su uso queda a juicio de los hablantes, debido a que en su lengua existe una lexía que tiene la misma función. Un ejemplo de ello, puede ser el neologismo buena vibra, recogida en el presente estudio y que de acuerdo con el análisis es equivalente a fino o chévere, en la variedad venezolana, por lo que su uso o naturalización se convierte en una segunda opción para el hablante.

Después de identificados y clasificados los neologismos, se procedió a aplicar el segundo método: el lexicográfico. Por eso, es necesario repasar, brevemente, su concepción teórica. La lexicografía se instauró como disciplina lingüística que construye repertorios léxicos y que reflexiona sobre estos a partir de una metodología propia, poseedora de técnicas, criterios y pasos para la confección de dichos repertorios, así como para la selección del material léxico que engloba. En ese sentido, la afirmación de Lara (1997) constituye una revelación de importancia al indicar que:

(...) la lexicografía es una disciplina que tiene por objeto definir y enseñar los métodos y los procedimientos que se siguen para escribir diccionarios. Es decir, que la lexicografía no es una ciencia, sino una metodología. El diccionario, especialmente, el diccionario monolingüe, en cambio, es un fenómeno verbal que antecedió históricamente a la constitución de su propia metodología, porque fue un resultado de la evolución de la cultura en varias civilizaciones, particularmente en la europea, y de la manera en que se dio la reflexión sobre las lenguas maternas dentro de ellas (p. 17-18).

De la tesis de Lara (1997), se pericbe que la lexicografía es teoría y metodología porque admite la elaboración de diversos repertorios léxicos (diccionarios, glosarios e inventarios), a partir de sus propios procedimientos, análisis y reflexión. Considerando que, en el método lexicográfico el léxico es la manifestación experiencial de una comunidad de hablantes o lo que Lara (2006, p. 213) denomina representación de las concepciones, valores y tabúes sociales. De allí, que se haya concebido como primer criterio del método lexicográfico, la representatividad del léxico, es decir, aquellas unidades utilizadas constantemente por los miembros de una comunidad de hablantes y que responden a diversos elementos lingüísticos y sociales.

Este criterio se ha aplicado al léxico utilizado por los diarios antes mencionados: EN, UN, EU y LR en el periodo 2011-2012, poseedores de neologismos y préstamos lingüísticos que a su vez evidencian elementos lingüísticos y sociales. Entre los elementos lingüísticos de dichos fenómenos léxicos se han destacado 
los sentidos que posee un vocablo, mientras que entre los elementos sociales se ha percibido el uso real de dicho vocablo, que luego puede utilizarse en la elaboración y compilación de un repertorio. De esta forma, los neologismos y préstamos recopilados en la prensa escrita venezolana se consideran vocablos, ya que tienen una estructura y sentido en contextos y/o situaciones comunicativas particulares.

A la tesis esbozada por Lara (2006), se le han sumado las consideraciones de Fajardo (2010, p. 323), quien indica que el método lexicográfico cuenta con otros criterios para la selección del material léxico, entre los que se encuentran: a) selección a partir del corpus textual, apoyado por textos primarios de autores de prestigio. En otras palabras, la documentación de vocablos utilizados en contextos y que se han coleccionado en obras literarias, hemerográficas e incluso lexicográficas; b) selección por base lexicográfica, a saber, por contrastividad y reelaboración de nuevos repertorios tomando como referencia la existencia de otros; c) selección del léxico diferencial, el cual consiste en la oposición de una variedad lingüística con respecto a otra (español de uso venezolano con respecto al español peninsular); y d) selección del léxico integral o descriptivo, considerado como el registro de un conjunto de voces que no han sido comparadas.

De los criterios del método lexicográfico señalados en el párrafo anterior, se han utilizado los dos primeros. En el caso del primer criterio: selección del material a partir del corpus textual, Fajardo (2010) indica que:

(...) siguen un método de trabajo «de primera mano» que tiene sus raíces en la tradición inaugurada en España por el Diccionario de autoridades de la Real Academia Española (1732-37) que optó por documentar cada palabra apoyándose en textos primarios (de autores de prestigios) que servían como ejemplo en cada definición, procedimiento (p. 323).

En cuanto al segundo criterio, selección por base lexicográfica, se ha recurrido a la contrastividad, la cual es entendida como la comparación y verificación de las lexías seleccionadas -en este caso los neologismos y préstamos lingüísticoscon el Diccionario de la Real Academia Española (DRAE) (2001) para comprobar su aparición o no en dicho repertorio. Sobre la técnica de contrastividad, Tejera (1994) asevera que:

Es necesario que la contrastividad se establezca mediante la comparación con una obra lexicográfica y no con el uso. Es decir, que al confrontar un término dialectal con la codificación, tal y como la presenta otro diccionario, podrá establecerse en que niveles existen diferencias. En cambio, si el 
contraste se establece por conocimiento del uso que el lexicógrafo posee de la otra modalidad o por encuestas, pueden producirse confusiones o errores (p.17).

El criterio de contrastividad, de algún modo, ha coincidido con el criterio de comprobación de unidad léxica propuesto para la identificación y validación del neologismo y que ha sido aplicado en la presente investigación para evaluar si los neologismos y préstamos lingüísticos recopilados aparecen y/o poseen o no el mismo significado con respecto al DRAE $(2011)^{1}$ para incluirlos en el análisis de este estudio.

Otro aspecto metodológico propio de la lexicografía, para la recolección del material léxico ha sido la distinción del léxico, que a juicio de Lara (2006) se divide en: a) vocabulario fundamental, léxico con el que cuenta un grupo de hablantes para comunicarse; b) vocabulario activo, léxico empleado por el hablante en su vida cotidiana, a saber, vocabulario de actuación primaria; c) vocabulario pasivo, léxico aprendido que se usa de acuerdo intereses laborables, de estudio, artísticos, etc.; y d) vocabulario disponible, léxico memorizado que se utiliza en determinadas situaciones por los hablantes, de acuerdo a factores como la edad, sexo, educación, conocimiento, entre otros (p. 148-164).

De esta concepción, se ha considerado que los neologismos y préstamos lingüísticos recopilados en la presente investigación se encuentran dentro del vocabulario activo y disponible debido a que, su aparición en la prensa escrita en el periodo 2011-2012 demuestra su utilización en el día a día y en las distintas situaciones comunicativas por un grupo de hablantes, quienes han apelado al conocimiento y a la memoria para referirse a un hecho o acontecimiento. De este modo, los neologismos y préstamos lingüísticos se han considerado "listas de vocablos" que poseen los hablantes.

Esta presunción ha supuesto que el material léxico recopilado haya sido estudiado exhaustivamente debido a que interesa su estructuración y significación (Lara, 2006, p.153). Esto permitió el empleo de otro aspecto del método lexicográfico: el análisis, el cual consiste en el reconocimiento de los rasgos sémicos y/o características de los neologismos y préstamos lingüísticos dentro del contexto determinado.

1. Al inicio de la esta investigación (2011) aún no había sido publicado la versión más reciente del Diccionario de la Real Academia Española (DRAE) (2014), de allí que se haya empleado en la presente investigación la versión del año 2001. Aunque muy bien pudo hacerse, finalmente, se optó por utilizar esa, dado que el estudio, contempla solo la prensa escrita del periodo 2011-2012. 
El reconocimiento de estos rasgos sémicos y/o características de los neologismos y préstamos lingüísticos se ha complementado con el criterio de tipologización y clasificación de los neologismos. Ello hizo posible conocer la clase y/o tipología de ellos y su proceso de formación y el reconocimiento y selección de dichas unidades léxicas. Así, un neologismo como estandupero, cumple con los principios que conciernen a la forma, específicamente con la sufijación. Al mismo tiempo, se evidencia que es un neologismo semántico, debido a que no existe un nombre para referirse a la persona que realiza un stand up comedy.

Criterios que sirven para interpretar y constatar cómo se producen las mediaciones culturales en las distintas comunidades lingüísticas y su posterior relación, pues, al indicar que un neologismo o préstamo lingüístico es necesario, da por sentada la apropiación y adaptación de estos fenómenos léxicos a la comunidad de hablantes en la que se inserta. Por otro lado, estas pautas propician la selección, análisis y descripción del corpus, es decir, los neologismos y préstamos lingüísticos aparecidos en la prensa escrita venezolana entre el 2011 y 2012.

\section{Resultados}

Es necesario resaltar que todo estudio sobre léxico -y lexicografía- se halla en permanente revisión por tratarse de fenómenos que constantemente se muestran dinámicos y cambiantes en las diversas situaciones comunicativas, por lo que un estudio de esta naturaleza no puede considerarse concluido. Por el contrario, constantemente, habrá que volver a él para verificarse, revisarse y por ende, ampliarse. Así, los resultados van en consonancia con el periodo de tiempo en el que se han consultado los medios impresos antes señalados.

Por otro lado, los resultados de la presente investigación se dividen en dos apartados. En el primero, se evidencia la formación y adquisición de los neologismos y préstamos lingüísticos y cómo permiten la mediación entre culturas; en el segundo, se muestra un inventario lexicográfico sobre los fenómenos estudiados a partir de los usos y aparición en la prensa escrita seleccionada. 


\section{Los neologismos y préstamos lingüisticos aparecidos en la prensa escrita venezolana en el periodo 2011-2012}

Verificación de los neologismos. Aplicado el primer método de análisis a los diarios seleccionados se ha obtenido el siguiente corpus:

Tabla 2. Tipo y contexto de neologismos

\begin{tabular}{|c|c|c|c|}
\hline Neologismo & $\begin{array}{l}\text { Tipo de neolo- } \\
\text { gismo }\end{array}$ & $\begin{array}{l}\text { Necesario/No } \\
\text { necesario }\end{array}$ & Contexto (uso) \\
\hline $\begin{array}{l}\text { actividad } \\
\text { crediticia }\end{array}$ & Sintagmación & Necesario & $\begin{array}{l}\text {... como al consumo y la inversión, y a la } \\
\text { fuerte actividad crediticia por parte de del } \\
\text { sistema financiero. }\end{array}$ \\
\hline Baby gym. & Préstamo & Necesario & $\begin{array}{l}\text { Los bebés tienen un espacio acondicionado } \\
\text { en el Baby Gym. }\end{array}$ \\
\hline Dogout & Préstamo & Necesario & $\begin{array}{l}\text { Un ambiente diferente en el dogout melenu- } \\
\text { do. (LR, } 17 \text { de noviembre de 2011, p. 18). }\end{array}$ \\
\hline $\begin{array}{l}\text { estandupero, } \\
\text { a }\end{array}$ & Sufijación & Necesario & $\begin{array}{l}\text { ¿Cómo se come eso de que "yo soy un } \\
\text { estandupero"? (EU, } 18 \text { de marzo de } 2012, \\
\text { p. 3-4). }\end{array}$ \\
\hline Imparable & $\begin{array}{l}\text { Prefijación y } \\
\text { sufijación }\end{array}$ & No necesario & $\begin{array}{l}\text { Alex Romero disparó un imparable remolca- } \\
\text { dor... (EU, } 13 \text { de noviembre de 2011, p. 2-2). }\end{array}$ \\
\hline Red social & $\begin{array}{l}\text { Por } \\
\text { sintagmación }\end{array}$ & Necesario & $\begin{array}{l}\text { hablamos cada vez con más frecuencia } \\
\text { de las redes sociales. (UN } 11 \text { de marzo de } \\
\text { 2012, p. 16) }\end{array}$ \\
\hline Sabermétrica & Por acronimia & Necesario & $\begin{array}{l}\text { En esa estadística sabermétrica, el vene- } \\
\text { zolano ocupaba hace dos años el lugar } 29 \\
\text { de todos los tiempos... (EN, } 04 \text { de marzo de } \\
\text { 2012, p. 1). }\end{array}$ \\
\hline Scout & Préstamo & Necesario & $\begin{array}{l}\text {...se dispone a correr las } 60 \text { yardas frente a } \\
\text { dos docena de scouts... (EN, } 04 \text { de marzo } \\
\text { de 2012, p.3). }\end{array}$ \\
\hline Team work. & Préstamo & Necesario & $\begin{array}{l}\text { El nuevo dirigente tendrá la tarea de re- } \\
\text { construir no solo el record del Caracas sino } \\
\text { construir un team work... (LR, } 17 \text { de marzo } \\
\text { de 2011, p. 10). }\end{array}$ \\
\hline Twitter & Préstamo & Necesario & $\begin{array}{l}\text {... reportaron a través de la red social twit- } \\
\text { ter... (UN } 11 \text { de marzo de 2012, p. 18). }\end{array}$ \\
\hline Buena vibra & $\begin{array}{l}\text { Por } \\
\text { sintagmación }\end{array}$ & No necesario & $\begin{array}{l}\text { La buena vibra es parte de un concepto... } \\
\text { (EN, } 10 \text { de marzo de 2012, p. 16). }\end{array}$ \\
\hline
\end{tabular}

Fuente: elaboración propia 
Para comprender cómo funcionan los neologismos y préstamos lingüísticos, es necesario revisar, una vez más, la concepción sobre el léxico de uso venezolano. Particularmente, se ha recurrido a la tesis esbozada por Rosenblat (1989), quien indica que el léxico de uso venezolano es innovador, creativo, propenso a la expresión figurada y al humor, así como cambiante y permeable. Estas particularidades se perciben tanto en las urbes como en los pueblos, en donde abundan comunidades de habla con diversas características que aportan nuevos elementos para enriquecimiento del español de Venezuela.

En el mismo sentido, Chumaceiro y Álvarez (2004) indican que "No se puede hablar de léxico del español de Venezuela sin decir que tiene una fisonomía propia, un carácter particular que le viene dado por los procesos de su conformación y de su posterior desarrollo” (p. 174). Dicho desarrollo, posiblemente, se ha debido a la adopción y surgimiento de neologismos y préstamos lingüísticos, los cuales no sólo han permitido la nominalización, explicación o descripción de hechos, situaciones o acciones nuevas, también han propiciado la interrelación de culturas disímiles, hasta el punto de emparentarlas y finalmente, constituirse en una sola.

Bajo esta premisa, se puede indicar que los neologismos y préstamos lingüísticos han revitalizado no sólo el léxico de una lengua, sino los modos de ver y pensar de una comunidad, debido a que permiten la creación, incorporación y uso de nuevas lexías para designar y significar una realidad. Al mismo tiempo, propician la relación y comunión de dos culturas distintas. No obstante, para comprender como el léxico evidencia la relación entre diferentes culturas, es necesario contemplar la noción de cultura como un proceso semiótico, tal como lo indica Geertz (2003).

Entendida como sistemas en interacción de signos interpretables (que, ignorando las acepciones provinciales, yo llamaría símbolos), la cultura no es una entidad, algo a lo que puedan atribuirse de manera causal acontecimientos sociales, modos de conducta, instituciones o procesos sociales; la cultura es un contexto dentro del cual pueden describirse todos esos fenómenos de manera inteligible, es decir, densa. (p. 27).

Si la cultura es un proceso semiótico, cuyos signos han permitido la interpretación y descripción de los acontecimientos, conductas o procesos sociales de los fenómenos humanos, los neologismos y los préstamos lingüísticos pueden constituirse en esos signos que han de propiciar el acercamiento y la reciprocidad entre los miembros de una comunidad ante eventos o situaciones, aparentemente, carentes de nombres y que necesitan ser denominados o descritos. Esta 
situación se ha podido constatar en la dinámica actual, cuya vorágine tecnológica favorece el surgimiento de artefactos, objetos, actividades o nuevas teorías que necesitan: a) nombrarse, b) explicarse y c) describirse. Para ello, se han creado nuevas palabras o, como ocurre en algunos casos, se han tomado de otro sistema lingüístico, tal como ha sido el caso de Redes sociales y Twitter.

En el caso de la lexía Redes sociales, se concibe como un neologismo por sintagmación, cuya formación y sentido se añadió al léxico de uso venezolano -y en español en general- gracias a las nuevas formas de comunicación e información originadas por tecnologías como Facebook o Twitter, aplicaciones que favorecen la relación y comunicación entre las personas en tiempo real y sin importar las distancias. Asimismo, el uso en español de este neologismo parece servir de contrapeso a su par anglosajón: Social networks. De este modo, Redes sociales, se puede tomar como un calco del inglés que conserva su significado y que supone su utilización no sólo en la prensa escrita, sino en los medios audiovisuales y más aún por los hablantes.

Por su parte, la lexía simple Twitter, relacionada con Red social, en un principio se ha concebido como un préstamo sin alteración que se acepta desde el punto de vista morfológico y fónico. No obstante, por el uso reiterado y por sugerencia de la Real Academia Española (RAE), la forma anglosajona se ha españolizado y ha originado "tuiter", lo que da a entender que es un préstamo plenamente integrado a la lengua, ya que, se ha adaptado desde el punto de vista fonético así como gráfico (Otaola, 2004, p.79). A pesar de esto, la voz Twitter continúa siendo un préstamo lingüístico porque no se ha creado otra forma para denominar este medio de comunicación y de información en la lengua española, cuya característica principal es la economía del lenguaje, debido permite en 140 caracteres transmitir y enviar mensajes de manera instantánea.

Lo anterior, evidencia que el uso de las lexías Redes sociales y Twitter sirven como puntos de encuentro y comunión entre dos culturas: la hispana y la anglosajona, lo que muestra la permanente relación y retroalimentación que subyace entre ambas. Este hecho deja entrever la apropiación y adopción de elementos culturales a partir de los neologismos antes descritos y que de algún modo, cumplen la postura de Geertz (2003, p. 27), a saber, signos de comunicación dentro de un contexto particular, en este caso, el campo tecnológico que origina la creación de una serie de lexías adoptadas por la mayoría de los hablantes, tanto del habla inglesa como de la española. Esta última, al carecer de un equivalente propio, recurre a la forma originaria y sin implementar mayores cambios, lo que reafirma la tesis de que la lengua revela el patrimonio cultural de 
un grupo de hablantes (Coseriu, 1986, p. 62) y, al mismo tiempo la necesidad de mostrar aquellas experiencias sociales de la vida cotidiana y que forman parte de la dinámica comunicacional actual.

Similar caso se aprecia con la lexía compuesta Sabermétrica, neologismo por acronimia procedente del inglés sabermetrics, que se españolizó para designar una nueva metodología -a partir del análisis estadístico- que evalúa el rendimiento de los jugadores de beisbol. Esta lexía, aparte de ser un neologismo por acronimia, funciona como calco semántico porque sólo ha tomado el significado sin significante, para luego traducir la estructura semántica que produce el nuevo significante (Otaola, 2004, p. 80). Una vez que el préstamo ingresa al sistema lingüístico que lo adopta y modifica, se convierte en una unidad léxica necesaria, cuya función puede ser la de describir y explicar una situación o evento particular. Con la lexía sabermétrica se pone en evidencia los lazos e influencia de la cultura norteamericana entre los hablantes del español de Venezuela, a través del beisbol, deporte con muchos seguidores venezolanos, cuya jerga -en su mayoría proveniente del inglés norteamericano- ha logrado penetrar en la comunicación diaria, lo que comprueba, a juicio de los autores del presente estudio, el encuentro cultural.

Dicho encuentro se constata en la adopción de este neologismo por los periodistas y especialistas del beisbol, quienes lo usan para explicar aspectos relacionados con la disciplina, lo cual ratifica la influencia de la lengua inglesa al momento denominar y describir alguna situación de esta actividad; ello es propicio para describir el encuentro y la confluencia de dos culturas en una sola lexía. Semejante situación se percibe en Scouts, neologismo por préstamo lingüístico, que mantiene su forma original en el significante porque no se producido otra lexía igual o similar en la lengua receptora; de allí que se integra sin ningún tipo de alteración a la comunidad de habla que la adopta o se apropia de ella.

Esta unidad léxica -Scouts-, al igual que Sabermétrica, es utilizada generalmente en la jerga beisbolística con sus sentidos originales: a) observador y caza talentos de los jugadores noveles y b) visitador de estadio, es decir, "espía" del equipo contrario para conocer sus debilidades; ante la ausencia de un equivalente exacto en el español de Venezuela se utiliza su forma originaria, comprobando, una vez más, la retroalimentación y mediación entre culturas.

Hasta ahora, se ha indagado sobre los neologismos (Red social y Sabermétrica) y dos préstamos lingüísticos (Twitter y Scouts) obtenidos de la prensa escrita y que el receptor/lector entiende y comprende porque ha logrado hasta 
ahora familiarizarse con dichas unidades léxicas. Esto quizás, como consecuencia de que dichos fenómenos son utilizados y posiblemente integrados al léxico de uso venezolano, gracias a los medios de comunicación, tanto escrito como audiovisual, lo que sugiere su establecimiento y aceptación en la dinámica cotidiana de los hablantes venezolanos, reflejadas en conversaciones, discusiones o reportajes que permiten explicar detalles o hechos particulares.

La misma situación pareciera ocurrir con la locución nominal buena vibra y la lexía simple estandupera. En el caso del primer neologismo, es producto de la sintagmación, es decir, es la unión de dos lexías, cuyo uso se refiere a una situación que causa placer, paz o gusto; es, tal vez, la contraparte de la voz anglosajona "cool" que no se utiliza mucho entre los hablantes venezolanos. Posiblemente, puede ser el equivalente de las voces "fino" o "chévere" que pertenecen al léxico de uso venezolano y, por tanto, su manejo está más extendido.

Por su parte, estandupero es un neologismo por sufijación e invención de forma, ya que se le agrega a la raíz de la palabra el sufijo ero, era, propio del español para indicar, en la mayoría de los casos, la profesión u oficio de una persona, por ejemplo "zapatero" producto de zapat + ero. En el caso del neologismo mencionado, es un calco de la voz inglesa "stand up", aunque también puede tomarse como un préstamo plenamente integrado en una lengua, desde el punto de vista fónico y gráfico porque se ha españolizado a estandu, lo que ha permitido formar derivados como estandupero o estandupera. La formación y uso de este neologismo se ha facilitado por el surgimiento de montajes teatrales como Stand up comedy, lo que ha propiciado la creación de la lexía mencionada para referirse a las personas que se dedican a esta actividad artística.

A partir de la lexía estandupero,- ra, se puede afirmar como los préstamos lingüísticos y neologismos median y propician el encuentro de dos culturas diferentes; incluso, la existencia y llegada del nombre de una actividad teatral como "Stand up" ha introducido otras y novedosas formas del quehacer artístico, ya que se adopta y adapta la palabra y se recibe la información, los modos de pensar, la visión e incluso las aptitudes y actitudes, además de ser signos que se utilizan en una situación particular. En el caso de esta lexía, estandupero, -ra, se ha popularizado porque los comediantes y humoristas venezolanos se encuentran realizando Stand up comedy; ello significa la creación de una nueva práctica de la que no se había tenido ningún registro o antecedente, al mismo tiempo que se han incorporado aspectos foráneos, que se han adecuado al discurso venezolano. 
El uso de cada uno de estos neologismos y préstamos lingüísticos confirma que la lengua se ha convertido en vehículo de mediación y encuentro cultural; esto, porque permite la adopción, utilización y por extensión comunicación entre hablantes dispares, lo que propicia la adquisición de distintos modos de mirar, pensar e incluso sentir, reafirmando lo dicho por Cahuzac (1993): "La lengua es un producto de la vida en sociedad (...) es con la organización léxica con quien se vincula la vida cotidiana”. (p. 97). Esta apreciación coincide con la aseveración de que el neologismo es un vocablo que da cuenta y significa una nueva experiencia en la vida social (Lara, 2006, p. 223) y que al mismo tiempo ha proporcionado la comunión y vinculación de distintas culturas.

Lo anterior se puede sustentar con la tesis de Chumaceiro y Álvarez (2004, p. 19), quienes han aseverado que el actual español de América, y por extensión el español de uso venezolano, es producto de la transculturación lingüística, económica, social, tecnológica, cultural y mediática. Esto permite entender la adquisición de nuevas formas de denominación o surgimiento de lexías como imparable, ampliamente usada dentro del ámbito deportivo, específicamente, en el beisbol, deporte muy seguido y practicado en Venezuela.

Este neologismo no es necesario, debido a que el uso original hit, proveniente del inglés, se utiliza también en las diversas situaciones comunicativas. No obstante, imparable funciona como equivalente en español producto de la prefijación y sufijación y al mismo tiempo por convergencia de significado. En ese sentido, su uso y creación denotan y comprueban que una lengua se puede apropiar de elementos de otra cultura y, al mismo tiempo, transformarlo o adoptarlo para denominar situaciones particulares o desconocidas hasta ese momento.

Caso parecido se puede encontrar con los neologismos por préstamos como: Dogout, Team Work y Baby Gym incorporados como lexías necesarias que conservan su forma original, porque no poseen o no se han creado los respectivos equivalentes en la variedad venezolana. Esto denota que funcionan como complementos, ampliación, así como apropiación de realidades distintas en la lengua española -y en particular a la venezolana-. También se puede evidenciar en dichas lexías rasgos de la sociedad norteamericana, las cuales se suman a la realidad lingüística y cultural del grupo humano receptor, en este caso venezolano.

Esta particularidad más que denigrar u opacar una lengua, la enriquece, y al mismo tiempo incorpora elementos con los cuales no se cuentan en los procesos comunicativos diarios y que han de ser necesarios para los hablantes. Asimismo, 
responde a la vorágine actual de un mundo globalizado en el que la lengua funge como mediadora para la adecuación y convivencia de las distintas culturas y de la raza humana, al mismo tiempo que demuestra la vitalidad y dinamismo de un sistema lingüístico. Para avalar esta afirmación se ha propuesto en el próximo apartado una suerte de Inventario con los neologismos y préstamos lingüísticos.

\section{Inventario de neologismos y préstamos lingüísticos usados en la prensa escrita venezolana 2011-2012}

En el presente estudio, los neologismos y préstamos lingüísticos aparecidos en la prensa escrita venezolana se han referido, la mayoría de las veces, a avances tecnológicos, práctica de alguna actividad deportiva, descripción de las actividades financieras o al ámbito de la farándula o espectáculo. Por tratarse de fenómenos léxicos que dan cuenta de la riqueza y vitalidad de una lengua, se han agrupado en un inventario lexicográfico.

Dicho inventario tiene como función los siguientes aspectos: a) descripción (suerte de definición) de las unidades léxicas; b) explicación del procedimiento de neología (formación); c) evidenciar los tipos de neologismos según los criterios esbozados por el Observatori de Neologia y de Alcoba Rueda (op.cit.); y d) constituirse en un artefacto que da cuenta de la cultura de un grupo humano. La estructuración de este inventario cuenta con una macroestructura y microestructura cuya explicación se puede ver a continuación:

\section{Macroestructura}

La macroestructura de este inventario está integrada por 11 unidades léxicas entre neologismos y préstamos lingüísticos a los cuales se les ha denominado Lemas agrupados a su vez en Artículos lexicográficos y ordenados de manera alfabética.

\section{Unidades lexémicas}

El inventario de neologismos y préstamos lingüísticos utilizados en la prensa escrita en el periodo 2011-2012 incluye los lexemas que se han clasificado en simples y compuestos-complejos. De igual modo, se han considerado locuciones. Estos aspectos se pueden observar a continuación:

Lexemas simples: consta de una sola unidad léxica y se lematiza según el género (masculino/femenino): 
dogout. $m$. Lugar en el que aguardan los jugadores y cuerpo técnico de un equipo de beisbol. $\boldsymbol{\nabla}$ Neologismo necesario, aunque existe el uso cueva. Préstamo lingüístico de forma y de significado. * Disciplina deportiva. Un ambiente diferente en el dogout melenudo. (LR, 17 de noviembre de 2011, p. 18).

Lexema compuesto y complejo: es producto de la unión de dos o más palabras sin conector ortográfico y su significado equivale a cada una de sus partes.

sabermétrica. $f$. Estudio estadístico utilizado para analizar el rendimiento de los jugadores de beisbol. $\boldsymbol{\Lambda}+\boldsymbol{\nabla}$. Neologismo y préstamo necesario. $\square$ Por acronimia. * Disciplina deportiva. En esa estadística sabermétrica, el venezolano ocupaba hace dos años el lugar 29 de todos los tiempos... (EN, O4 de marzo de 2012, p. 1).

Locuciones: se diferencian de los lexemas compuestos y complejos en la unión de sus partes, lo que origina un significado general, es decir, cohesión semántica. Además, son construcciones estables y en algunos casos institucionalizadas.

team. $\sim$ work. loc. nom. Equipo deportivo o grupo de personas que trabajan de manera cohesionada y por un mismo objetivo. $\boldsymbol{\nabla}$ Neologismo necesario. Por préstamo lingüístico. * Disciplina deportiva. El nuevo dirigente tendrá la tarea de reconstruir no solo el record del Caracas sino construir un team work... (LR, 17 de marzo de 2011, p. 10).

\section{Lematización y ordenación}

La mayoría de los lemas de este inventario son sustantivos y se lematizan por la flexión masculino singular:

imparable. $m$. Pelota golpeada por un bate sin posibilidad de ser atrapada $\boldsymbol{\Delta}$. Neologismo no necesario, debido a que también se utiliza la forma inglesa Hit. Prefijación y sufijación. * Disciplina deportiva. Alex Romero disparó un imparable remolcador... (EU, 13 de noviembre de 2011, p. 2-2).

Oflexión femenino-singular.

sabermétrica. $f$. Estudio estadístico utilizado para analizar el rendimiento de los jugadores de beisbol. $\boldsymbol{\Lambda}+\boldsymbol{\nabla}$. Neologismo y préstamo necesario. $\square$ Por acronimia. * Disciplina deportiva. En esa estadística sabermétrica, el venezolano ocupaba hace dos años el lugar 29 de todos los tiempos... (EN, O4 de marzo de 2012, p. 1). 
Si el género de la unidad léxica presentase ambas flexiones, aparece primero la moción masculina, seguida de la coma y la posterior terminación femenina. Igualmente, se coloca la marca gramatical:

estandupero, a. $m / f$.y adj. [Persona] que realiza Stand up comedy (\| Show teatralizado en la que una persona cuenta anécdotas personales a un público.). $\boldsymbol{\Delta}$ Neologismo necesario. De invención de forma por sufijación. * Ámbito cultural. ¿¿Cómo se come eso de que” yo soy un estandupero”? (EU, 18 de marzo de 2012, p. 3-4).

\section{Lexema compuesto}

Este lema que se forma de la unión de dos palabras se coloca sin ningún signo que las separe:

sabermétrica. $f$. Estudio estadístico utilizado para analizar el rendimiento de los jugadores de beisbol. $\boldsymbol{\Delta}+\boldsymbol{\nabla}$. Neologismo y préstamo necesario. $\boldsymbol{\square}$ Por acronimia. * Disciplina deportiva. En esa estadística sabermétrica, el venezolano ocupaba hace dos años el lugar 29 de todos los tiempos... (EN, o4 de marzo de 2012, p. 1).

\section{Locuciones}

Aquellos lemas que se lematizan por la palabra que posea mayor carga semántica o nuclear:

actividad. $\sim$ crediticia. loc. nom. Operación bancaria referida a las solicitudes de préstamos y/o créditos. $\boldsymbol{\Delta}$. Neologismo necesario. $\boldsymbol{\square}$ Por sintagmación. * Actividad financiera. ... como al consumo y la inversión, y a la fuerte actividad crediticia por parte de del sistema financiero". (ÚN 11 de marzo de 2012, p. 13).

Tipografía de los lemas

Todos lemas (simples, compuestos y locuciones) se incluyen en negritas y minúscula al inicio y terminan en un punto. Mientras que las marcas gramaticales se encuentran en cursiva. 


\section{Microestructura}

Información gramatical: se presenta seguida del lema, en letra minúscula y abreviada, tal como se muestra a continuación en los casos masculino y femenino:

imparable. $m$. Pelota golpeada por un bate sin posibilidad de ser atrapada $\boldsymbol{\Delta}$. Neologismo no necesario, debido a que también se utiliza la forma inglesa Hit. — Prefijación y sufijación. * Disciplina deportiva. Alex Romero disparó un imparable remolcador... (EU, 13 de noviembre de 201 1, p. 2-2).

sabermétrica. $f$. Estudio estadístico utilizado para analizar el rendimiento de los jugadores de beisbol. $\boldsymbol{\Delta}+\boldsymbol{\nabla}$. Neologismo y préstamo necesario. $\boldsymbol{\square}$ Por acronimia. * Disciplina deportiva. En esa estadística sabermétrica, el venezolano ocupaba hace dos años el lugar 29 de todos los tiempos... (EN, O4 de marzo de 2012, p. 1).

Para los casos del que lema comparta doble género y doble categoría gramatical se ha dispuesto de la siguiente manera:

estandupero, a. $m / f \cdot y$ adj. [Persona] que realiza Stand up comedy (\| Show teatralizado en la que una persona cuenta anécdotas personales a un público.). $\mathbf{\Delta}$ Neologismo necesario. $\mathbf{D}$ De invención de forma por sufijación. * Ámbito cultural. ¿Cómo se come eso de que ” yo soy un estandupero"? (EU, 18 de marzo de 2012, p. 3-4).

No se determinan otras categorías gramaticales, debido a que todos los neologismos y préstamos lingüísticos encontrados son sustantivos, excepto un lema cuya categoría gramatical es adjetivo. De igual modo, no presenta otras marcas (pragmática ni sociolingüística).

\section{Las definiciones $y / o$ descripciones}

Las definiciones se conciben como descripciones lingüísticas. Para ello, se tomaron los siguientes criterios: a) las definiciones son lexicográficas. Se evitaron las enciclopédicas o circulares; b) en algunos casos se usaron definiciones propias y/o sinonímicas que puedan cumplir con la ley de sustitución; c) los lemas, cuya categoría gramatical es sustantivo - mayoría de los casos de este inventario- se 
han definido con otro sustantivo. Igualmente, se recurre a la definición parafrástica y en metalengua de contenido y de signo; d) las definiciones son neutras y objetivas, sin ningún tipo de valoración personal, ideológica y/o social; las definiciones mantienen, en la medida de lo posible, la unidad sintáctica; y f) se ha intentado que las definiciones sean claras y precisas, para ello se ha utilizada la lengua estándar, tal como lo ha hecho el Diccionario de Real Academia Española (DRAE) (2011).

\section{Tipo y procedimiento de los neologismos y préstamos lingüísticos}

Se determinó ubicar la información sobre el proceso de creación. Para tal fin, se tomó en cuenta: a) el procedimiento de neología, dividido por la forma, ya sea morfología regular como prefijación, sufijación o composición y por el significado, que puede ser por lexía compleja, conversión o expresión figurada; y b) la clase de neologismos que se ha contemplado si es necesario o no es necesario. Esta clasificación se ha introducido por un símbolo.

\section{Ejemplos}

Los ejemplos de estos fenómenos léxicos responden a los usos que provienen de cada una de las proposiciones que han aparecido en la prensa escrita del periodo 2011-2012, lo cual se convierte en una fuente de autoridad que expresa no sólo cómo dos culturas permean y median entre, sino la definición un grupo lingüístico.

\section{$\underline{\text { Abreviaturas y símbolos }}$}

Tabla 3. Abreviaturas y símbolos

\begin{tabular}{|l|l|}
\hline \multicolumn{1}{|c|}{ Abreviaturas } & \multicolumn{1}{c|}{ Símbolos } \\
\hline adj.: Adjetivo. & $\mathbf{\Lambda}:$ Indica neologismo necesario o no necesario. \\
EN: El Nacional. & $\mathbf{\nabla}:$ Indica préstamo lingüístico no necesario. \\
EU: El Universal. & $\mathbf{\Delta}+\mathbf{\nabla}:$ Indica neologismo y préstamo \\
f: Sustantivo femenino. & lingüístico. \\
LR: Líder & a: Introduce tipo de neologismo y préstamo \\
m: Sustantivo masculino. & lingüístico. \\
loc. nom.: Locución nominal. & *: Se refiere al ámbito de uso del neologismo y \\
UN: Últimas Noticias. & préstamo lingüístico. \\
& 川: Indica subacepción. \\
& $\sim:$ Sustituye al lema cuando es una locución. \\
\hline
\end{tabular}

Fuente: elaboración propia 


\section{Inventario de los neologismos y préstamos}

actividad. $\sim$ crediticia. loc. nom. Operación bancaria referida a las solicitudes de préstamos y créditos. $\mathbf{\Lambda}$. Neologismo necesario. - Por sintagmación. * Actividad financiera. ... como al consumo y la inversión, y a la fuerte actividad crediticia por parte del sistema financiero". (ÚN 11 de marzo de 2012, p. 13).

baby. $\sim$ gym. loc.nom. Espacio anexo al gimnasio en donde cuidan a los bebés.

Préstamo lingüístico necesario. — Por préstamo. * Espacio de recreación. Los bebés tienen un espacio acondicionado en el Baby Gym. (EN, O4 de marzo de 2012, p. 2).

dogout. $m$. Lugar en el que aguardan los jugadores y cuerpo técnico de un equipo de beisbol. $\mathbf{\nabla}$ Préstamo lingüístico necesario, aunque existe el uso cueva. - Por préstamo. * Disciplina deportiva. Un ambiente diferente en el dogout melenudo. (LR, 17 de noviembre de 2011, p. 18).

estandupero, a. $m / f$.y $a d j$. [Persona] que realiza Stand up comedy (\| Show teatralizado en la que una persona cuenta anécdotas personales a un público.). $\boldsymbol{\Delta}$ Neologismo necesario. — De invención de forma por sufijación. * Ámbito cultural. ¿Cómo se come eso de que” yo soy un estandupero"? (EU, 18 de marzo de 2012, p. 3-4).

imparable. $m$. Pelota golpeada por un bate sin posibilidad de ser atrapada $\boldsymbol{\Lambda}$ Neologismo no necesario, debido a que también se utiliza la forma inglesa Hit. Prefijación y sufijación. * Disciplina deportiva. Alex Romero disparó un imparable remolcador... (EU, 13 de noviembre de 2011, p. 2-2).

red. $\sim$ social. loc.nom $\boldsymbol{\Delta}$. Conjunto de aplicaciones como Facebook o Twitter, utilizadas en la web para comunicarse y/o establecer relaciones con otras personas. $\Delta$ Neologismo necesario. - Por sintagmación. * Ámbito tecnológico. ... hablamos cada vez con más frecuencia de las redes sociales. (UN 11 de marzo de 2012, p. 16). Obs.: Utilizado en plural redes sociales.

sabermétrica. $f$. Estudio estadístico utilizado para analizar el rendimiento de los jugadores de beisbol. $\boldsymbol{\Lambda}+\boldsymbol{\nabla}$. Neologismo y préstamo necesario. $\mathbf{~ P o r ~ a c r o - ~}$ nimia. * Disciplina deportiva. En esa estadística sabermétrica, el venezolano ocupaba hace dos años el lugar 29 de todos los tiempos... (EN, 04 de marzo de 2012, p. 1). 
scout. m.y adj. El que observa, analiza y contrata nuevos jugadores. $\nabla$ Préstamo lingüístico necesario. - Por préstamo. * Disciplina deportiva. ... se dispone a correr las 60 yardas frente a dos docena de scouts... (EN, O4 de marzo de 2012, p.3).

team. work. loc. nom. Equipo deportivo o grupo de personas que trabajan de manera cohesionada y con un mismo objetivo. $\boldsymbol{\nabla}$ Préstamo lingüístico necesario. Por préstamo. * Disciplina deportiva. El nuevo dirigente tendrá la tarea de reconstruir no solo el record del Caracas sino construir un team work... (LR, 17 de marzo de 2011, p. 10).

twitter. $m$. Red social que permite la comunicación entre varias personas en un máximo de 140 caracteres. $\nabla$ Préstamo lingüístico necesario. @ Por préstamo. * Ámbito tecnológico. ... reportaron a través de la red social twitter... (UN 11 de marzo de 2012, p. 18).

vibra. buena $\sim$. loc.nom. Situación o persona agradable $\boldsymbol{\Delta}$. Neologismo no necesario debido a que existe el uso venezolano chévere o fino. Por sintagmación. * Ámbito social. La buena vibra es parte de un concepto... (EN, 10 de marzo de 2012, p. 16).

\section{Conclusiones}

El léxico constituye el componente que refleja los modos de ser de una comunidad; en ese sentido cobra fuerza la propuesta de Lara (2006, p. 213), al indicar que este componente lingüístico es un símbolo social porque representa las experiencias de los hablantes y, por ende, de las dos culturas que entran en contacto. En ese sentido, los neologismos y préstamos lingüísticos han sido muestra de ello. A partir de ello se derivan las siguientes conclusiones:

- Los neologismos y préstamos lingüísticos muestran el día a día de una comunidad de hablantes; al mismo tiempo se convierten en un "puente" entre dos culturas y permite las relaciones, adquisiciones y adopciones de nuevas experiencias; tal como se aprecia en los casos de estandupero, sabermétrica, twitter y baby gym.

- Los neologismos y préstamos lingüísticos encontrados en el presente estudio evidencian las características dadas por Alcoba (2007). Por ejemplo, el neolo- 
gismo y el préstamo lingüístico actividad crediticia y dogout, son necesarios y esenciales en los procesos comunicativos diarios.

- Los fenómenos léxicos enriquecen la lengua receptora porque incluye otros vocablos y/o signos lingüísticos que agilizan y diversifican los procesos comunicativos entre los integrantes de una comunidad de hablantes. Este hecho comprueba que la lengua no es estática, por el contrario constantemente se cambia y se adapta a las diversas circunstancias y situaciones comunicativas de los hablantes.

- Del análisis de los neologismos y préstamos lingüísticos se confecciona un Inventario lexicográfico que puede visualizarse como un artefacto lingüístico-cultural que da cuenta de los modos de creación de un conjunto de voces, así como de los usos que le otorga un grupo de hablantes a dichos vocablos.

- Un inventario lexicográfico de neologismos y préstamos lingüísticos certifica las características de estos fenómenos léxicos: su posible significado, su tipología, si es necesario o no y si constatan la mediación entre dos culturas. Todo ello permite concluir que los repertorios lexicográficos son representaciones de la vitalidad de una lengua, así como del universo sociocultural de la comunidad de hablantes que representa.

\section{Referencias}

Alcoba, S. (2007). Autorización y uso de los neologismos. En Sarmientos, R. y Vilches, F. (Coord.). Neologismos y sociedad del conocimiento funciones de la lengua en la era de la globalización. España: Fundación Telefónica y Editorial Ariel. S.A.

Aleza, M. y Enguita, J. M. (Coord.). (2010). La lengua española en América: normas y usos actuales. Universitat de Valencia. Recuperado de: http://www.uv.es/ aleza/Cap.\%207.\%20EA\%20Lexicog\%20prim\%20part.pdf.

Baldinger, K. (1970). Teoría semántica. Hacia una semántica moderna. España: Ediciones Alcalá.

Cahuzac, Ph. (1993). La división del español de América en zonas dialectales. En F. Moreno Fernández. (Ed.). La división dialectal del español de América. España: Alcalá de Henares. 
Castillo, C. (2003). La macroestructura del diccionario. En A. M. Medina Guerra (Coord.). Lexicografía española. Barcelona: Ariel.

Chela-Flores, G. (1998). Orígenes y estado actual del español de Venezuela. Venezuela: Comisión Regional Macuro 500 años.

Chumaceiro, I. y Álvarez, A. (2004). El español, lengua de América. Venezuela: El Nacional.

Coseriu, E. (1986). Introducción a la lingüística. España: Editorial Gredos.

Diario El Nacional (noviembre 2011 y marzo 2012). En esa estadística sabermétrica, el venezolano ocupaba hace dos años el lugar 29 de todos los tiempos (04 de marzo de 2012, p. 1).

Diario El Universal (noviembre 2011 y marzo 2012). ¿Cómo se come eso de que” yo soy un estandupero”? (18 de marzo de 2012, p. 3-4).

Diario Líder (noviembre 2011 y marzo 2012). Un ambiente diferente en el dogout melenudo (17 de noviembre de 2011, p. 18).

Diario Últimas Noticias (noviembre 2011 y marzo 2012). Reportaron a través de la red social twitter (11 de marzo de 2012, p. 18).

Fajardo, A. (2010). La lexicografía del español de América. En M. Aleza Izquierdo J. M. Enguita Utrilla (Coords.). La lengua española en América: normas y usos actuales. Universitat de Valencia. Recuperado de: http://www.uv.es/ aleza/Cap.\%207.\%20EA\%20Lexicog\%20prim\%20part.pdf.

Geertz, C. (2003). Interpretación de las culturas. España: Gedisa Editorial.

Lara, L. F. (2006). Curso de lexicología. México: El Colegio de México.

Lara, L. F. (1997). Teoría del diccionario monolingüe. México: El Colegio de México.

Lugo, T. (1996). Neologismos rusos en el campo económico. Núcleo, 13, 37-55.

Martínez, O. (s. f.). Cultimos. Recuperado de: http://www.dialnet.unirioja.es/servlet/fichero_articulo?codigo=910354. 
Medina, A. (Coord.) (2003). Lexicografía española. España Ariel.

Meza, D., Arrieta, B. y Batista, J. T. (2007). Criterios de necesidad en neologismos utilizados por docentes universitarios. Letras, 74, 57-83.

Moreno, F. (1993). (Ed.). La división dialectal del español de América. España: Alcalá de Henares.

Observatori de Neologia. (2004). Metodología de trabajo en neología: criterios, materiales y procesos. Papers de l' IULA. Serie Monografies, 9. Barcelona: Universitat Pompeu Fabra. Institut Universitari de Lingüística Aplicada.

Otaola, C. (2004). Lexicología y Semántica léxica. España: Ediciones Académicas.

Quiroga, L. (1991). Los neologismos y la lengua española. Letras, 48, 59-67.

Real Academia de la Lengua (2001). Diccionario de la lengua española. $21^{\text {era }}$ ed. España: Espasa-Calpe.

Rosenblat, Á. (1989). Biblioteca Ángel Rosenblat, II. Estudios sobre el habla de Venezuela. Buenas y malas palabras. Venezuela: Monte Ávila.

Tejera, M. J. (1994). Discurso de incorporación como individuo de número. Caracas: Academia Venezolana de la Lengua. 